\title{
Estrategias de sostenibilidad para la isla Tierra Bomba basadas en el concepto de estructura ecológica principal
}

\author{
Sustainable strategies for Tierra Bomba Island based \\ on the concept of main ecological structure
}

\author{
Cristian Herrera Atencio*, Cristina Cabrera Martínez ${ }^{* * *}$ y Claudia Díaz Mendoza ${ }^{* * * *}$
}

Citar este artículo como: Herrera Atencio, C.; Cabrera Martínez, C. y Díaz Mendoza, C. (2018). Estrategias de sostenibilidad para la isla Tierra Bomba basadas en el concepto de estructura ecológica principal. Revista Nodo, 12(24), 21-31

\section{Resumen}

La investigación de la cual da cuenta este artículo trata de aportar una gestión ambiental territorial de ejecución conjunta entre el Estado, la academia y las comunidades como resultado de un modelo de gestión basado en estrategias de sostenibilidad, formuladas a partir de la aplicación, en un ámbito local insular, del concepto de Estructura Ecológica Principal (EEP), y tomando como caso de estudio la isla de Tierra Bomba. Las estrategias de sostenibilidad propuestas buscan, a partir de los recursos naturales e interacciones sociales, orientar las acciones de preservación, restauración, uso sostenible y actividades productivas, en función de los elementos biofísicos que hacen parte de la EEP de la isla por participar en el desarrollo de su función social y ecológica; que además se están viendo afectados negativamente en cuanto a calidad, extensión y conectividad fundamentalmente por procesos de expansión urbana inadecuados, con el consecuente aumento en extensión y magnitud de las construcciones presentes en el litoral y en el suelo continental y la reducción de las fronteras entre los asentamientos urbanos y los biomas de la isla.

Palabras clave: Ecología, Desarrollo sostenible, Administración y planificación de tierras, Ordenamiento ecológico.

\begin{abstract}
The research carried out aims to provide territorial environmental management of the joint execution between the State, the Academy and the Communities as a result of a management model based on sustainability strategies, formulated from the application, in a local insular domain, of the concept of Main Ecological Structure (MES), and
\end{abstract}

Fecha de recibo: 17 de mayo de 2018 - Fecha de aceptación: 28 de junio de 2018

\footnotetext{
* Ingeniero Ambiental. Joven Investigador del programa de Ingeniería Ambiental, Fundación Universitaria Tecnológico Comfenalco, Cartagena, Colombia. Correo electrónico: cherreraa@tecnocomfenalco.edu.co

* Bióloga con énfasis en Ecología. Grupo de Investigaciones Ambientales (GIA), Fundación Universitaria Tecnológico Comfenalco, Cartagena, Colombia. Correo electrónico: ncabrera@tecnologicocomfenalco.edu.co

*** Ingeniera Civil, Especialista en Ingeniería Sanitaria y Ambiental, Máster en gestión y Auditoria Ambiental. Grupo de Investigaciones Ambientales (GIA), Fundación Universitaria Tecnológico Comfenalco, Cartagena, Colombia. Correo electrónico: cdiaz@tecnologicocomfenalco.edu.co
} 
taking as a case study the island Tierra Bomba. The proposed sustainability strategies seek, from the natural resources and social interactions, to guide the actions of preservation, restoration, sustainable use and productive activities, based on the biophysical elements that are part of the MES of the Island for participating in the development of its social and ecological function. These are also being negatively affected in terms of quality, extension and connectivity, fundamentally due to inadequate urban expansion processes, with the consequent increase in the extension and magnitude of the constructions present in the littoral and on the continental soil and the reduction of the borders between urban settlements and the biomes of the Island.

Keywords: Ecology, Sustainable development, Land Administratión and planning, Ecological planning.

\section{Introducción}

El sistema insular que emerge sobre el Mar Caribe colombiano lo componen islas e islotes de diferente origen y composición. Y de acuerdo con su localización en esta área marítima se clasifican como islas continentales, al ascender sobre la plataforma continental y estar cerca de las áreas continentales; e islas oceánicas, al ascender distantes de la plataforma y separarse de ésta por fosas marinas profundas (Instituto de Hidrología Meteorología y Estudios Ambientales (IDEAM, 2010). Las islas continentales del Caribe colombiano son Tierra Bomba, del Rosario, Barú, San Bernardo, Fuerte y Tortuguilla; y las oceánicas son el Archipiélago de San Andrés, Providencia y Santa Catalina.

En términos generales las islas presentan procesos naturales y dinámicas socioambientales similares a las de las áreas continentales; sin embargo, la distancia que separa los territorios insulares de los continentales es una condición determinante en los procesos de interacción entre los elementos biofísicos del territorio y las dinámicas socioambientales que se den sobre éste.
Estas interacciones modelan el desarrollo social, económico y natural con base en los ecosistemas continentales y costeros, los recursos naturales y servicios ecosistémicos confinados en el territorio insular, por lo que sus elementos biofísicos evolucionan y experimentan cambios positivos o negativos en función del tipo, forma e intensidad de las interacciones y la capacidad de resiliencia del territorio. Sumado a las variaciones de tamaño, forma y nivel generados por los cambios climáticos globales que amenazan de manera especial a los territorios insulares; en general los territorios insulares están expuestos a procesos de erosión-sedimentación y retroceso de la línea de costa como consecuencia de factores marinos tales como el oleaje, las mareas y el aumento del nivel del mar. Las principales variaciones en cuanto a la composición de los territorios insulares se dan sobre los elementos biológicos, de relieve y las formas de uso, manejo y ocupación del suelo litoral y continental.

En los últimos años, la explotación de los recursos naturales ubicados sobre la extensión continental de las áreas insulares ha cobrado gran interés de inversión privada, dada las ventajas competitivas y comparativas que poseen en cuanto a su localización geográfica, oferta de recursos naturales y servicios ecosistémicos; pero en ocasiones se realiza con desconocimiento de la diversidad biológica que allí habita y de las interacciones que se dan entre ésta y los demás elementos físicos y actores sociales del territorio. Esto ha llevado a subestimar los impactos y perturbaciones que pueden generar o que han generado presiones antropogénicas en la integridad ecológica de los territorios insulares.

De esta manera surge la necesidad de confrontar el grado de integración ecológica de los territorios insulares del Caribe colombiano y establecer para ellos, de manera especial y pertinente, estrategias de sostenibilidad que actúen como elementos motrices de las dinámicas socio-ambientales y socio-económicas del territorio en cuestión y principios estructurantes de un proceso de ordenamiento territorial. 
Bajo este panorama surge la necesidad de definir el concepto de Estructura Ecológica Principal (EEP) del territorio en cuestión (Márquez \& Valenzuela, 2008; Valbuena, Tavera \& Palacios, 2008; Van Der Hammen, 1998; Van Der Hammen \& Andrade, 2003). Este enfoque conceptual plantea una visión territorial hacia la integración ecológica, teniendo como objetivo la planificación fundamentada en la inclusión de la dimensión ambiental en el ejercicio de ordenamiento territorial dictaminado por ley, dado que agrupa todos los espacios del patrimonio natural que son imprescindibles para soportar el desarrollo sostenible y sustentable de las comunidades asentadas en un territorio (Remolina, 2011). En este sentido, se constituye en un soporte técnico científico de posibles lineamientos para el manejo integral para un territorio y los instrumentos de gestión que haya lugar, de manera que se aseguren los recursos naturales, los procesos productivos y la calidad de la vida (Andrade, Remolina, Wiesner \& Montenegro, 2014).

\section{Isla de Tierra Bomba}

La Isla de Tierra Bomba está ubicada sobre el Mar Caribe y pertenece al distrito de Cartagena de Indias. Se localiza al sur oeste del mismo, en el departamento de Bolívar y limita al norte con la entrada a la bahía de Cartagena denominada canal Bocagrande, al este con la bahía de Cartagena, al sur con la entrada a la bahía denominada canal Bocachica y al oeste con el Mar Caribe (Figura 1).

La isla cuenta con una superficie aproximada de $20.18 \mathrm{~km}^{2}$, posee una variada topografía con zonas bajas, mesetas y colinas y un litoral costero que incluye playas, acantilados y zonas cenagosas con manglares. En su extensión continental soporta los corregimientos de Bocachica, localizado al sursureste de la isla; Caño del Oro, localizado al este y Tierra Bomba, localizado al norte (a este último pertenece el centro poblado conocido como Punto Arena).

Además cuenta con atractivos asociados con su localización geográfica en el trópico, su posicio-

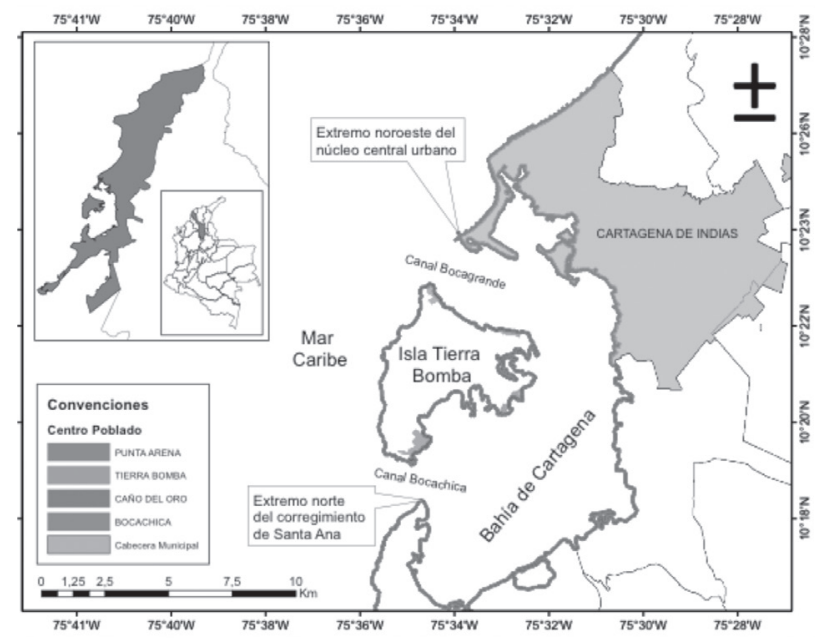

Figura 1. Mapa de localización de la isla de Tierra Bomba. Fuente: elaboración propia

namiento marino dada la ubicación de la isla entre el Mar Caribe y la bahía de Cartagena, su paisaje interno (con una variedad de ecosistemas estratégicos como manglares y reductos de bosques secos tropicales), patrimonios arqueológicos y con una visual circundante privilegiada hacia el mar, la bahía de Cartagena y el distrito (Rizo Pombo, Emiliani Callejas, Fegali Corena, \& Rizo Delgado, 2011). Por lo que en la isla las principales actividades productivas son las pesca y el turismo.

No obstante, en la isla se ha propiciado una dependencia socioeconómica sobre sus componentes biofísicos con un alto grado de desaprovechamiento y/o uso inadecuado del territorio, como consecuencia de unas políticas públicas de planificación y gestión que ignoran la función social y ecológica del mismo.

Como resultado, puede observarse un panorama de planificación altamente disociador de la función social y ecológica del territorio, que ha generado una exacerbada presión antrópica sobre los recursos naturales y los bienes de uso público de la isla, producto de una contrastante dualidad en su panorama de habitabilidad. Por un lado se refuerza su potencial turístico y portuario y sus condiciones de paraíso natural con la aquiescencia de los entes gubernamentales; y por otro lado, estos 
mismo desconocen, minimizan y/o controlan de manera poco efectiva las condiciones de pobreza, la deficiencia en la prestación de servicios públicos básicos, la mala disposición de residuos sólidos, los vertimientos inadecuados de aguas residuales, los conflictos sociales por el desplazamiento de la población y/o los cambios en la estructura de la tenencia de la tierra, el retroceso de la línea de costa producto de la erosión costera, los cambios en los usos del suelo litoral y continental y los cambios en las prácticas sociales, culturales y actividades económicas.

En consecuencia, la isla se constituye en un importante foco de atención a la hora de plantear y adoptar lineamientos o estrategias de desarrollo sostenible que permitan trascender hacia un contexto mucho más pertinente en términos de necesidades, uso, manejo y aprovechamiento de los recursos naturales; y establecer límites de acción antrópica sobre el territorio y sus recursos naturales.

\section{Metodología}

La investigación se ejecutó en cinco fases de trabajo. La primera implicó la caracterización biofísica del territorio en estudio definiendo en primera instancia su entorno ambiental regional que lo confina; en la segunda, se generó una línea base de información biofísica del territorio, en cuanto a su climatología, oceanografía, geología, geomorfología, hidrografía y biomas, a partir de la información bibliográfica disponible de la isla; en la tercera fase se realizó un análisis de los cambios de cobertura de tierra del territorio en estudio en una línea de tiempo, cuya ventana de observación fue desde el año 1960 hasta el 2015. La selección de los diferentes escenarios en la línea de tiempo estuvo condicionada a la capacidad de obtener información histórica por medio de imágenes satelitales.

La imagen más antigua obtenida data de 1969 y fue recuperada de la base de datos del U.S. Geological Survey (USGS); la imagen del año 1969 fue comparada con imágenes disponibles de años en las décadas siguientes hasta identificar un año a partir del cual se evidenciarán cambios visuales significativos sobre la cobertura de tierra de la isla. Esta condición se evidenció en una imagen del año 2000 que luego fue comparada con el límite superior de la ventana de observación. Las imágenes usadas para los años 2000 y 2015 se captaron de los satélites Landsat-7-ETM+ y Sentinel-2A, respectivamente; compuestas por 3 bandas espectrales, con resolución espacial de $30 \mathrm{~m}$ y radiométrica de 8-bits.

La comparación de la cobertura de tierra de la isla en la línea de tiempo se realizó clasificando las imágenes de los años 2000 y 2015, de acuerdo con la leyenda CORINE Land Cover adaptada para Colombia, mediante clasificación supervisada e interpretación visual en el software ArcGis versión 10.3, corroborando con observaciones de campo, consultas a comunidades locales e información secundaria. Lo anterior permitió realizar un análisis histórico de la cobertura de tierra de la isla, en el que se identificaron y cuantificaron los tipos de cobertura de tierra presentes y los posibles tensores ambientales asociados a cada uno por año analizado.

En la cuarta fase de trabajo y de acuerdo con la información generada anteriormente, se definió la EEP del territorio en estudio. Los elementos biofísicos que hacen parte de la EEP, se seleccionaron de acuerdo con los siguientes criterios de incorporación: 1) integración de la biodiversidad, a partir de la delimitación de elementos y/o unidades biogeográficas con representatividad ecológica, 2) provisión de servicios ecosistémicos, a partir de la identificación de las interacciones entre los elementos biofísicos, y 3) satisfacción de necesidades humanas, a partir de la identificación de los tensores ambientales sobre elementos biofísicos.

Por último, como fase final del proceso investigativo, a partir de la EEP de la isla, y mediante un enfoque sistémico de ordenamiento territorial, se formulan las estrategias de planificación y ordenamiento para la misma. 


\section{Resultados y discusión}

\section{Entorno ambiental regional}

El entorno ambiental regional del que hace parte la isla de Tierra Bomba lo conforma la zona costera de la región Caribe colombiana, que para efectos prácticos, se restringirá a la franja marina comprendida entre el extremo norte del corregimiento de Santa Ana (Cartagena, Bolívar) y el extremo noroeste del núcleo central urbano del distrito de Cartagena.

Dado el medio costero definido como entorno ambiental regional para la isla y por la localización de la misma en él, se distinguen dos espacios marinos: el primero corresponde a la franja marina seleccionada del litoral Caribe colombiano extendida sobre los límites del distrito de Cartagena de Indias y el segundo corresponde a la bahía de Cartagena (Figura 1).

Con relación a la parte del entorno ambiental regional delimitado como franja marina del litoral Caribe colombiano, se tiene que el medio marino que lo conforma guarda las mismas características del Mar Caribe colombiano. Ubicado en la zona tropical, el entorno marino se ve influenciado principalmente por los fenómenos meteorológicos de la zona de convergencia intertropical, los vientos alisios, el paso de las ondas tropicales del este y los frentes fríos provenientes del hemisferio norte (Afanador Franco, Orozco Quintero, Gómez Mojica, \& Carvajal Díaz, 2008).

El entorno ambiental regional, delimitado por la bahía de Cartagena, se comunica con el Mar Caribe a través de dos bocas: una ubicada en el sector suroccidental de la bahía que es más estrecha, Bocachica, que permite el desarrollo de las actividades portuarias y, otra ubicada en el sector noroccidental, Bocagrande, más cercana a la ciudad y más amplia pero solo navegable para embarcaciones de pequeño calado debido a una escollera artificial que la atraviesa y que restringe considerablemente el intercambio de masas de agua entre la bahía y el mar abierto (Díaz \& Gómez, 2003). En ella se desarrollan actividades relacionadas con la zona franca portuaria e industrial del distrito y turísticas; adicionalmente se ve influenciada por las aguas que le descarga el Canal del Dique, el cual desemboca en su extremo sureste.

En este contexto, ambos sectores analizados dentro del entorno ambiental regional de la isla condicionan, por sus características naturales y antrópicas, los procesos marino-costeros, la presencia de elementos bióticos, procesos ecológicos y servicios ecosistémicos y los impactos de los fenómenos climáticos de origen marino y continental que se dan sobre la isla condicionando a su vez por los factores socioeconómicos y políticoadministrativos que intervienen en su desarrollo.

\section{Componentes biof ísicos del territorio}

Seguidamente, en cuanto a la línea base de información biofísica del territorio, ésta se generó sobre su climatología, oceanografía, suelo que la soporta y biomas. La Isla, al igual que el distrito de Cartagena, posee un clima tropical semiárido (Centro de Investigaciones Oceanograficas e Hidrograficas (CIOH, 2010); y como en toda el área marítima del Caribe colombiano, los principales fenómenos oceanográficos que amenazan la isla son el alto oleaje y los mares de leva relacionados con el paso de fenómenos atmosféricos y el aumento del nivel del mar relacionado con los cambios climáticos globales, además de manera particular la isla también se ve afectada por la dinámica de los aportes de sedimentos continentales provenientes principalmente del río Magdalena y el Canal del Dique, influenciados por las corrientes marinas de zona.

El suelo que soporta la isla, le corresponde el mismo contexto geológico del Caribe colombiano referente a su configuración geotectónica, asociado al Bloque Norandino, en adelante BNA (Invemar \& ANH (ANH, 2010), y morfo-estructural, asociada a las formación de La Popa, formaciones arrecifales y cuaternarias que afloran en el Cinturón del Sinú sobre el cual se ubica la isla (Ingeominas \& Alcaldía de Cartagena de Indias, 2001; Universidad 
de Cartagena \& Alcaldía de Cartagena de Indias, 2010). Por otro lado, su configuración geomorfológica parte de la geomorfología submarina de la región Caribe colombiana, que se caracteriza por presentar relieves positivos, escarpes, antiformas, canales enterrados y posibles zonas de emanación de fluidos (Invemar \& ANH, 2010). La geomorfología continental de la isla esta discriminada en unidades geomorfológicas asociadas a costas altas, tales como lomas, plataformas de abrasión elevada y terrazas marinas, y unidades geomorfológicas asociadas a costas bajas, tales como playas, espigas, playones antiguos, pantanos intermareales y lagunas costeras (Carvajal \& Jurado, 2009; Posada Posada \& Henao Pineda, 2011).

Los biomas asociados a la isla que se presentan en el medio continental son un bosque seco tropical húmedo, compuesto por vegetación xerofítica y manglares, y en los alrededores de la isla, en el medio oceánico, pastos marinos y reductos de formaciones arrecifales.

La isla registra la presencia de vegetación xerofítica en el costado oriental sobre las laderas de las lomas, detrás de la línea de manglares y en los sectores más altos; estas áreas de vegetación han sido paulatinamente transformadas en áreas de cultivos transitorios y/o pastoreo. La zona de manglar en la isla se encuentra ubicada hacia el costado de la bahía de Cartagena, comprendido desde el sur del corregimiento de Tierra Bomba hasta el de Bocachica, y se presentan en forma de parches o franjas de diferente extensión; la zona más extensa se localiza al oeste de la isla donde aparecen encerrando ciénagas internas de diversos tamaños en forma de franjas angostas y continuas y como cuerpos aislados al sur y este de la isla. Sus diferencias en extensión se debe a que se está viendo fuertemente deteriorado por las intervenciones y/o actividades antrópicas tales como la tala, los rellenos para generar asentamientos, las quemas para la posterior siembra de cultivos, el turismo, su uso como vertedero de residuos sólidos y pozo séptico (Carvajal \& Jurado, 2009).

\section{Análisis del desarrollo histórico de la cobertura de tierra de la isla}

Para analizar el desarrollo de la cobertura de tierra de la isla a través del tiempo, se tuvo como ventana de observación desde el año 1960 hasta el año 2015, y se encontró que durante 31 años, al menos entre los años 1969 y 2000, la cobertura de la isla permaneció casi constante.

Posteriormente, en la mitad del tiempo, durante los 15 años transcurridos desde el año 2000 al 2015, la isla comenzó a tener progresivos y significativos cambios de cobertura. Esto se evidenció en las firmas espectrales de las imágenes satelitales usadas para los años 1969 hasta el año 2000; para el año 2015 la firma espectral observada denota los cambios de cobertura que experimentó el territorio.

De acuerdo con lo anterior se procedió a analizar la cobertura de tierra de la isla para los años 2000 y 2015, procesando las imágenes satelitales disponibles para llevarla a la leyenda CORINE Land Cover adaptada para Colombia, como se muestran en la Figura 2.

Espacialmente se observa un aumento descontrolado y errático del tejido urbano, en comparación con la disminución de la extensión de los biomas costeros y continentales. Esto es más evidente

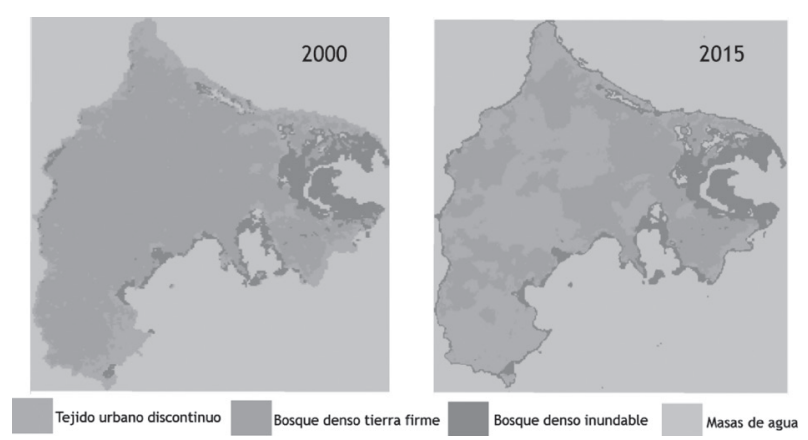

Figura 2. Comparación de la cobertura de tierra de la isla de acuerdo con la leyenda CORINE Land Cover adaptada para Colombia, entre los años 2000 y 2015. Fuente: Elaboración propia 
cuando se cuantifican las áreas de extensión de cada tipo de cobertura y la ganancia o pérdida en dicha medida, como se aprecia en la Tabla 1. El tejido urbano discontinuo aumentó en un $62 \%$ entre los años 2000 y 2015 mientras las unidades de biomas costeros y continentales de mayor representatividad ecológica en la isla, disminuyeron su extensión en un $61 \%$, en el mismo intervalo de tiempo.

Los cambios de cobertura de tierra identificados en la isla, pueden estar asociados a las interacciones socioambientales que dieron y se dan sobre el territorio en los intervalos de tiempo analizados. Estas interacciones socioambientales se identificaron a manera de tensores ambientales sobre los elementos biofísicos de la isla, previamente delimitados y dentro de los intervalos de
Tabla 1. Áreas y porcentajes de cambio por tipo de cobertura para la isla de Tierra Bomba entre los años 2000 y 2015

\begin{tabular}{|l|r|r|r|}
\cline { 2 - 4 } \multicolumn{1}{c|}{} & \multicolumn{2}{c|}{ Área $\left(\mathbf{k m}^{2}\right)$} & \% de \\
\hline \multicolumn{1}{|c|}{ Tipo de cobertura } & $\begin{array}{c}\text { Año } \\
\mathbf{2 0 0 0}\end{array}$ & $\begin{array}{c}\text { Año } \\
\mathbf{2 0 1 5}\end{array}$ & $\begin{array}{c}\text { cambio } \\
\text { Bosque denso inundable }\end{array}$ \\
\hline Bosque denso tierra firme & 14,82 & 2,03 & $-18 \%$ \\
\hline Tejido urbano discontinuo & 3,24 & 8,60 & $-43 \%$ \\
\hline
\end{tabular}

Fuente: Elaboración propia

tiempo analizados. Dicha información se plasmó en la Tabla 2, donde puede evidenciar que las situaciones de mayor riesgo ambiental se dan en combinación de tensores naturales como el oleaje en la bahía de Cartagena con tensores antrópicos

Tabla 2. Tensores ambientales identificados entre los años 1969 y 2015

\begin{tabular}{|c|c|c|c|}
\hline $\begin{array}{l}\text { Categoría } \\
\text { del suelo }\end{array}$ & $\begin{array}{l}\text { Unidad de cobertura } \\
\text { de tierra }\end{array}$ & Tensores ambientales & Actores \\
\hline \multicolumn{4}{|c|}{ Tensores ambientales identificados entre los años 1969-2000 } \\
\hline Suelo rural & Bosque denso tierra firme & $\begin{array}{l}\text { Extracción de madera para subsistencia } \\
\text { Agricultura }\end{array}$ & \multirow{3}{*}{ Población nativa } \\
\hline \multirow[b]{2}{*}{$\begin{array}{l}\text { Suelo } \\
\text { suburbano }\end{array}$} & Bosque denso inundable (Manglar) & Extracción de madera para subsistencia & \\
\hline & Tejido urbano discontinuo & $\begin{array}{l}\text { Construcción infraestructura } \\
\text { Oleaje de la bahía de Cartagena }\end{array}$ & \\
\hline \multicolumn{4}{|c|}{ Tensores ambientales identificados entre los años 2000-2015 } \\
\hline \multirow{4}{*}{ Suelo rural } & \multirow{4}{*}{ Bosque denso tierra firme } & Expansión urbana acelerada & \multirow{4}{*}{ Sectores privados } \\
\hline & & $\begin{array}{l}\text { Reducción de las fronteras entre los } \\
\text { asentamientos urbanos y el ecosistema }\end{array}$ & \\
\hline & & Cambios en la tenencia de la tierra & \\
\hline & & $\begin{array}{l}\text { Construcción de complejos } \\
\text { habitacionales turísticos }\end{array}$ & \\
\hline \multirow{4}{*}{$\begin{array}{l}\text { Suelo } \\
\text { suburbano }\end{array}$} & Bosque denso inundable (Manglar) & $\begin{array}{l}\text { Reducción de las fronteras entre los } \\
\text { asentamientos urbanos y el ecosistema } \\
\text { Vertimiento de aguas residuales }\end{array}$ & Población nativa \\
\hline & & Inadecuada disposición de residuos & \\
\hline & \multirow[b]{2}{*}{ Tejido urbano discontinuo } & Expansión urbana acelerada & \multirow{2}{*}{$\begin{array}{l}\text { Sectores privados } \\
\text { Población nativa }\end{array}$} \\
\hline & & $\begin{array}{l}\text { Construcción infraestructura } \\
\text { Oleaje de la bahía de Cartagena }\end{array}$ & \\
\hline
\end{tabular}

${ }^{1}$ De acuerdo con el POT vigente

${ }^{2}$ De acuerdo con la leyenda de cobertura de tierra CORINE Land Cover adaptada para Colombia Fuente: Elaboración propia 
asociados a la modificación de los litorales por la construcción de viviendas y/o infraestructura poblacional.

Adicionalmente, otros tensores antrópicos como la deforestación en combinación con la construcción de complejos habitacionales, está cambiando radicalmente la tenencia de tierra, por privatización, y el uso, manejo y ocupación que se daba a porciones del territorio ocupados por ecosistemas de bosques tropicales; asimismo los procesos de expansión urbana inadecuada tienen relación directa con la reducción de las fronteras entre los asentamientos urbanos y los ecosistemas de bosque y manglar, propiciando sobre estos últimos el vertimiento de aguas residuales y la inadecuada disposición de residuos al convertirlos en parte de sus predios.

De esta manera las consecuencias de estos y otros tensores sobre el territorio se ponen de manifiesto con efectos adversos sobre la sucesión y resiliencia ecológica, la calidad ambiental de los ecosistemas y/o biomas de la isla y la degradación o pérdida del suelo litoral y continental.

\section{Estructura Ecológica Principal (EEP)}

Se definieron los elementos que podrían hacer parte de la EEP de la isla, de acuerdo con el entorno ambiental regional, los elementos biofísicos actuales del territorio y la forma como históricamente se han integrado.

Los elementos biofísicos que interactúan y hacen parte de la isla, se presentan en la Figura 3. Estos elementos participan en el desarrollo de la función social y ecológica del territorio, por lo cual son tenidos en cuenta al momento de definir la EEP.

La EEP para la isla tiene como elementos tutelares los biomas de bosque seco y manglar, siendo importante como ordenadores del territorio por cuanto representan la mayor área del mismo y en el caso del manglar juega un papel adicional en cuanto a la protección costera del territorio.

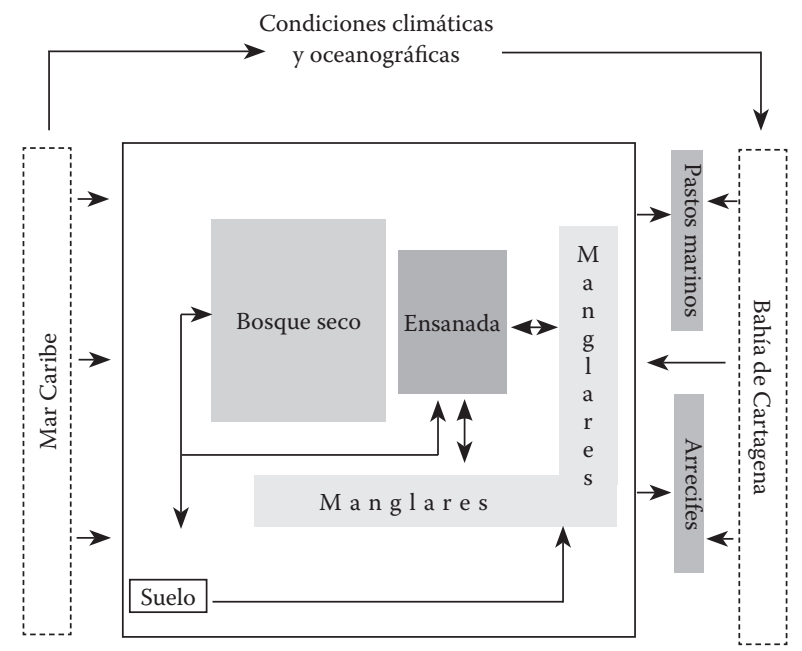

Figura 3. Elementos biofísicos que interactúan y hacen parte de la isla de Tierra Bomba. Fuente: Elaboración propia

Dada las condiciones actuales de la isla, se evidencia que la mayor problemática asociada a su EEP es la fragmentación que está experimentando de manera progresiva por lo que se propone un esquema de conectividad, teniendo como base la iniciativa ECCONET (European Ecological NetworK), que reclasifica los elementos incorporados en tres tipos esenciales: las zonas núcleo como espacios caracterizados por concentrar zonas de interés ecosistémico, que para la isla representan los biomas primarios de bosque denso de tierra firme y el bosque denso inundable (manglar); los conectores, que corresponderán a extensiones de los elementos representativos de las zonas núcleo para enlazarlos entre sí y generar una conexión entre las nuevas áreas de carácter paisajístico o recreativo con el resto de biomas primarios que conforman las zonas núcleo; y las zonas de amortiguación, que corresponderán a extensiones de los elementos representativos de las zonas núcleo destinadas a proteger otras áreas de interés dentro de la categoría de tejido urbano discontinuo; entendidas estas como otros espacios importantes pero de menor jerarquía a las zonas núcleo, como las áreas de desarrollo de actividades turísticas y/o productivas. 


\section{Modelo de gestión basado en estrategias de sostenibilidad usando el concepto EEP de la isla}

Una estrategia de sostenibilidad basada en la EEP es un esfuerzo para enlazar e integrar los diferentes niveles de planificación nacional, regional y local, planteando un uso sostenible y de desarrollo socioeconómico de las poblaciones ajustado a la realidad económica y social del territorio (Pérez Garcés, Zarate Yepes, \& Turbay Ceballos, 2011).

El uso del concepto de la EEP y la preservación de los elementos que incorpora en el territorio promueve el alcance de un patrón de sociabilidad más elevado de los recursos naturales y los servicios ecosistémicos contrario a su posible aislamiento a manera de "zonas de protección", que generalmente desemboca en medidas prohibitivas (Alfonso, 2009), difícilmente articulables a ciertas realidades de uso, manejo y ocupación del territorio.

Sobre la base de la discusión precedente, se propone el desarrollo un modelo de gestión basado en estrategias de planificación local con un enfoque sistémico y holístico de ordenamiento territorial para la sostenibilidad de la isla, a partir de la EEP definida y el contexto socioambiental inherente a la misma; incluyendo elementos de planificación que garanticen la sostenibilidad del territorio, al priorizar entre acciones de preservación, restauración, uso sostenible y actividades productivas. Como elementos del modelo de gestión propuesto se consideran tres tipos de estrategias de sostenibilidad, alrededor de la EEP de la isla.

La primera es la "Gestión del conocimiento", que tiene como objetivo construir una red de conocimiento, ejecutada en una escala de progresividad, para generar y divulgar información sobre los recursos naturales de la isla; y construir procesos de participación ciudadana y comunicación comunitaria para articular y promover en las comunidades el uso de prácticas tradicionales sostenibles de los recursos naturales.
La segunda tiene que ver con la "Integración de prácticas y modelos productivos", buscando promover, incentivar y/o diseñar proyectos de biocomercio con sistemas de aprovechamiento de recursos naturales in situ y su manejo sostenible, en el marco de una gestión ambiental rentable e implementando prácticas de restauración ecológica. Para lo cual los proyectos deben ser adaptados al entorno, justificando la decisión sobre el qué o cómo ejecutarse con base en criterios de límites ecológicos, y deben generar una rentabilidad no solo del capital económico también del capital ecológico y humano.

Y la tercera es la "Implementación de un Mercado Ambiental Local", entendiendo esto como la creación de un marco de acuerdos recíprocos entre las comunidades, el sector privado y el sector público, con estructuras legales, financieras y técnicas encaminadas a garantizar el ejercicio de la propiedad privada en consonancia con la EEP de la isla, dado que la isla está siendo objeto de un progresivo interés inversionista; dichas inversiones deberían ser coordinadas bajo un esquema de gobernanza que garantice su impacto socioambiental y su sostenibilidad, a través de herramientas existente o nuevos de carácter obligatorio, voluntario o mediado por las autoridades con jurisdicción.

\section{Conclusiones}

A partir de la discusión de los resultados de la investigación, se concluye que, de acuerdo con los cambios identificados en el territorio y los tensores ambientales posiblemente asociados, las consecuencias de estos sobre el territorio se ponen de manifiesto con efectos adversos sobre la sucesión y resiliencia ecológica y la calidad ambiental de los ecosistemas, en especial sobre los elementos biofísicos principales que hacen parte de la EEP de la isla (zonas núcleo), por participar en el desarrollo de su función social y ecológica.

Esto implica que la isla está en grave riesgo debido, entre otras cosas, a los diversos proyectos de intervención (inmobiliarios y hoteleros principalmente) 
sobre las zonas núcleo sin considerar las afectaciones que se generarían en cuanto a calidad, extensión y conectividad, evidenciado en los cambios de cobertura identificados.

Por ello se propone un modelo de gestión con tres grandes líneas de actuación, definidas como Estrategias de Sostenibilidad, que responden a los tres pilares del desarrollo sostenible (lo social, lo económico y lo natural); adaptadas a las necesidades evidenciadas en el contexto actual de la isla en cuanto a preservación, restauración y uso sostenible $\mathrm{o}$ actividades productivas, visualizado a través de la definición de la EEP de la isla. Se espera que estas estrategias de sostenibilidad puedan trascender hacia los instrumentos de ordenamiento y gestión ambiental territorial, para propender por un desarrollo sostenible y sustentable a partir de una intervención humana que realce el potencial de uso de los recursos naturales; el reto último, será la apropiación social e institucional no sólo de la inclusión de la EEP en los procesos de planificación sino de una gestión continua, participativa y adaptativa hacia la consecución de una EEP futura que responda a una visión a largo plazo del territorio en cuestión.

En este sentido, la base de lo natural requiere una gestión del conocimiento, desde una visión socio-ecológica que lo considere una construcción cultural; respecto a lo social se debe buscar la integración de prácticas y modelos productivos basados en los beneficios sociales de los recursos naturales que ofrece el territorio; y lo económico debe ser impulsado a partir de la implementación de un mercado ambiental local como mecanismo para escalar y dinamizar las estrategias anteriores.

Cabe destacar como conclusión que esta investigación presenta una experiencia cuyos resultados ratifican que lo principal para brindar oportunidades, más allá de las actividades que actualmente generan conflictos de uso, manejo y ocupación de un territorio, es entender cómo este está conformado y cuáles son sus tendencias de cambio. La definición de la EEP aporta a la consecución estos objetivos, debido a que para garantizar la función social y ecológica de los elementos biofísicos que la conforman, se debe integrar sosteniblemente los recursos naturales y las actividades socioeconómicas que se desarrollan en el territorio en cuestión.

\section{Referencias bibliográficas}

Afanador Franco, F., Orozco Quintero, F. J., Gómez Mojica, J. C., \& Carvajal Díaz, A. F. (2008). Ortofotografía digital y datos LIDAR para el control y administración del litoral en la isla de Tierra Bomba, Caribe colombiano. Boletín Científico CIOH, 26, pp. 86-103.

Alfonso, O. A. (2009). Economía institucional de la intervención urbanística estatal. Revista Territorios, Elaboración propia. 135-160.

Andrade, G., Remolina, F., Wiesner, D., \& Montenegro, F. (2014). La Estructura Ecológica Principal en lo local. Propuesta de aplicación en la renovación urbana de Fenicia, Las Aguas, Bogotá. Revista Nodo, 16(8), pp. 42-54.

Carvajal, A., \& Jurado, J. (2009). Caracterización físico-biótica del litoral del departamento de Bolívar. En Caracterización físico-biótica del litoral Caribe colombiano (p. 100). Cartagena: Dimar.

Centro de Investigaciones Oceanograficas e Hidrograficas [CIOH] (2010). Climatología de los principales puertos del Caribe colombiano: Cartagena de Indias D. T y C. Cartagena: $\mathrm{CIOH}$

Díaz, J., \& Gómez, D. (2003). Cambios históricos en la distribución y abundancia de praderas de pastos marinos en la bahía de Cartagena y áreas aledañas (Colombia). Boletín Investigaciones Marino Costeras, 32, 57-74.

Instituto Colombiano de Geología y Minería [INGEOMINAS], \& Alcaldía de Cartagena de Indias (2001). Zonificación geotécnica, aptitud y uso del suelo en el casco urbano de Cartagena de Indias, DTC - Bolivar. Cartagena: Servicio Geológico colombiano.

Instituto de Hidrología Meteorología y Estudios Ambientales [IDEAM]. (2010). Los Sistemas 
Insulares (SI). En Instituto de Hidrología Meteorología y Estudios Ambientales [IDEAM] (Ed.), Sistemas morfogénicos del territorio colombiano (p. 252). Bogotá: IDEAM.

Instituto de Investigaciones Marinas y Costeras [INVEMAR], \& Agencia Nacional de Hidrocarburos [ANH]. (2010). Biodiversidad del Margen Continental del Caribe Colombiano. Serie de publicaciones especiales (Vol. 20).

Márquez, G., \& Valenzuela, E. (2008). Estructura ecológica y ordenamiento territorial ambiental. Gestión y Ambiente, 11, pp. 137-148.

Pérez Garcés, H., Zarate Yepes, C. A., \& Turbay Ceballos, S. M. (2011). Conflictos ambientales: la biodiversidad como estrategia ordenadora del territorio.Projectsand conflictsassociated toaprior consultation. (English), 10, 57-72. Recuperado de http://search.ebscohost.com/login.aspx?direct= true \&db=lgh\&AN=73825132\&lang=es\&site $=e$ host-live

Posada Posada, B. O., \& Henao Pineda, W. (2011). Diagnóstico de la erosión costera del territorio insular colombiano. Bogotá: INVEMAR.

Remolina, F. (2011). Figuras municipales de conservación ambiental en Colombia: ¿áreas protegidas, redes ecológicas o infraestructuras verdes? Revista Nodo, 6(11), pp. 65-76.
Rizo Pombo, J. H., Emiliani Callejas, J. A., Fegali Corena, A., \& Rizo Delgado, S. L. (2011). Lineamientos generales para el desarrollo turístico integral de Tierra Bomba, con generación de recursos para beneficio de las comunidades de la isla y toda la población de Cartagena. Cartagena: Secretaria de Planeación Distrital.

Universidad de Cartagena, \& Alcaldía de Cartagena de Indias. (2010). Diagnóstico del distrito de Cartagena en materia de ordenamiento territorial (Producto entregable: Documento base para el expediente urbano distrital). Cartagena.

Valbuena, M. S., Tavera, H., \& Palacios, M. T. (2008). Propuesta de Estructura Ecológica Regional para la Región Central. Bogotá: Gobernación de Cundinamarca, Alcaldía Mayor de Bogotá, CAR de Cundinamarca, UNCRD-UNDESA \& Instituto de Investigación de Recursos Biológicos Alexander Von Humboldt.

Van Der Hammen, T. (1998). Plan ambiental de la Cuenca Alta del Río Bogotá: análisis y orientaciones para el ordenamiento territorial. Bogotá: CAR.

Van Der Hammen, T., \& Andrade, G. (2003). Estructura ecológica principal de Colombia: primera aproximación. Bogotá: Ideam. 